\title{
Perbandingan Pemberian Parasetamol Oral dan Ketorolak Intravena dalam Membantu Keberhasilan Menyusui Pasca Seksio Sesarea
}

\author{
${ }^{1}$ Dalri Nur Fidina, ${ }^{2}$ Ahsanudin Attamimi, ${ }^{3}$ Shinta Prawitasari \\ 1,2,3 Departemen Obstetri dan Ginekologi, Fakultas Kedokteran, Kesehatan Masyarakat dan Keperawatan UGM \\ Korespondensi: dinadalri@yahoo.com
}

Submisi:16 Januari 2020; Revisi:18 Mei 2020; Penerimaan: 19 Mei 2020

\begin{abstract}
Background: Difficulties in breastfeeding are the most frequent problems encountered in the early postnatal period, especially in mothers with caesarean section deliveries. An effective and adequate analgetic is needed for the mother's early mobilization post-surgery. Intravenous analgesics are commonly used but may inhibit mobilization and the postoperative care for the baby, therefore oral analgesics are an option because it is easily administered, simple, have a better drug tolerance, less side effects, inexpensive and can be given from 2 hours postoperatively.

Objective: The purpose of this study was to determine whether oral parasetamol $1000 \mathrm{mg}$ or ketorolac injection $30 \mathrm{mg}$ provides successful of breastfeeding after caesarean section

Methods: This study was a non blinding, randomized controlled trial. Patient were randomly into 2 groups assigned to receive either ketorolac injection $30 \mathrm{mg}$ (control group) or oral paracetamol $1000 \mathrm{mg}$. Visual analog scale (VAS) and LATCH score were administered postoperatively to assess pain levels and successful of breastfeeding 24 hours after caesarean section. Chi square and relative risk were used for statistical test for comparing two proportions.

Results and Discussion: The study recruited 86 subjects, there was no significant difference between paracetamol group and ketorolac group in provide pain relief $(R R 1,16 ; 95 \% C l 0,84-1,16)$. There was no significant difference in successful breastfeeding rate after caesarean secton in both of group with intervening variable no pain and pain.

Conclusions: Oral paracetamol $1000 \mathrm{mg}$ produces superior post-operative analgesia 1,16 compared to intravenous ketorolac 30 mg, however this result no significant difference to successful breastfeeding after caesarean section.
\end{abstract}

Keywords: paracetamol; ketorolac; caesarean section; successful of breastfeeding; pain

\begin{abstract}
ABSTRAK
Latar Belakang: Kesulitan menyusui merupakan masalah yang paling sering dihadapi pada awal masa pascasalin, terutama ibu dengan persalinan seksio sesarea. Anti nyeri yang efektif dan adekuat diperlukan ibu untuk dapat mobilisasi segera pasca operasi. Pemberian analgetik dalam sediaan intravena dapat menghambat mobilisasi dan proses merawat bayi pasca operasi, sehingga pemberian analgetik dalam sediaan oral menjadi salah satu alternatif terapi analgetik karena mudah diberikan, sederhana, toleransi obat baik, efek samping minimal, murah dan dapat diberikan sejak 2 jam pasca operasi.

Tujuan: Penelitian ini bertujuan untuk membandingkan pemberian parasetamol $1000 \mathrm{mg}$ oral dan injeksi ketorolak $30 \mathrm{mg}$ intravena dalam mengatasi nyeri terhadap keberhasilan menyusui pasca seksio sesarea.

Metode: Penelitian ini merupakan penelitian non blinding, randomized controlled trial yang membagi subyek penelitian menjadi 2 kelompok. Kelompok kontrol adalah kelompok yang mendapat injeksi ketorolak $30 \mathrm{mg}$ intravena dan kelompok perlakuan adalah yang mendapat parasetamol 1000 mg per oral yang kemudian dinilai nyeri dengan VAS dan keberhasilan menyusui dengan skor LATCH pada 24 jam setelah seksio sesarea. Chi square serta risiko relatif dipakai untuk uji statistik untuk membandingan 2 proporsi.

Hasil dan Pembahasan: Penelitian ini melibatkan 86 subjek. Pada pemberian parasetamol 1000 mg per oral dan ketorolak 30 mg intravena didapatkan hasil tidak perbedaan bermakna terhadap nyeri ( $R R$ 1,16; $95 \%$ Cl 0,84-1,16). Angka keberhasilan menyusui pada kedua kelompok dengan efek tidak nyeri dan nyeri didapatkan hasil tidak berbeda bermakna secara statistik.

Kesimpulan: Pemberian parasetamol 1000 mg per oral tidak berbeda bermakna dibandingkan dengan pemberian injeksi ketorolak 30 mg intravena terhadap nyeri dan keberhasilan menyusui pasca seksio sesarea.
\end{abstract}

Kata Kunci: parasetamol; ketorolak; seksio sesarea; keberhasilan menyusui; nyeri 


\section{PENDAHULUAN}

Air Susu Ibu (ASI) merupakan nutrisi ideal untuk bayi karena mengandung zat gizi yang paling sesuai dengan kebutuhan bayi dan zat perlindungan terhadap berbagai penyakit. World Health Organization (WHO) dan UNICEF merekomendasi pemberian ASI eksklusif selama 6 bulan pertama dilanjutkan hingga 2 tahun. Langkah-langkah yang dapat dilakukan untuk meningkatkan pemberian ASI eksklusif dengan melakukan Inisiasi Menyusu Dini (IMD) dalam 1 jam pertama kelahiran, memberikan ASI sesuai keinginan bayi, dan tidak menggunakan botol. ${ }^{1,2}$

Di Amerika Serikat kurang dari setengah populasi ibu yang menyusui bayi sampai usia enam bulan dan hanya $15 \%$ yang memberikan ASI eksklusif, sedangkan di Indonesia mengacu pada target renstra pada tahun 2015 sebesar 39\%, maka secara nasional cakupan pemberian ASI eksklusif pada bayi usia kurang dari enam bulan sebesar $55,7 \%$ telah mencapai target. ${ }^{3,4}$

Kesulitan menyusui merupakan masalah yang paling sering dihadapi pada awal masa pascasalin, terutama ibu dengan persalinan seksio sesarea. Angka seksio sesarea saat ini cukup meningkat baik di negara maju maupun negara berkembang, dimana sekitar 2\% di negara maju dan 21\% di negara berkembang. Di Amerika Serikat sendiri angka seksio sesarea meningkat dari $20,7 \%$ pada tahun 1996 menjadi 31,1\% di tahun 2006, sedangkan berdasarkan rekomendasi WHO angka seksio sesarea tidak lebih dari $15 \%$. Seksio sesarea berhubungan dengan rasa nyeri yang lebih hebat dibandingkan persalinan vaginal yang dapat menyebabkan nyeri akut hingga kronik. Salah satu dampak negatif yang ditimbulkan antara lain rasa tidak nyaman ibu sehingga menyebabkan kesulitan mobilisasi, menganggu dan menurunkan interaksi ibu dan bayi dalam proses menyusui yang mengakibatkan sekresi ASI tidak adekuat. ${ }^{5,6}$

Anti nyeri yang efektif dan adekuat diperlukan ibu untuk dapat mobilisasi segera pasca operasi sehingga dapat melakukan perawatan terhadap bayi. Regimen analgetik yang ideal diberikan adalah yang dapat memberikan pereda nyeri optimal dengan efek samping minimal terhadap ibu dan bayi melalui sekresi ASI, serta mudah diberikan. Berbagai intervensi pemberian analgetik yang efektif telah dilakukan dalam mengatasi nyeri pasca seksio sesarea, salah satu prosedur pemberian analgetik yang saat ini sering digunakan adalah pemberian analgetik parenteral yang kemudian dilanjutkan dengan pemberian analgetik oral 24-48 jam pasca operasi, namun pemberian dalam sediaan intravena dapat menghambat mobilisasi dan proses merawat bayi pasca operasi. Pemberian analgetik dalam sediaan oral menjadi salah satu alternatif terapi analgetik pasca seksio sesarea karena mudah diberikan, sederhana, toleransi obat baik, efek samping minimal, murah dan dapat diberikan sejak 2 jam pasca operasi karena hanya sebagian kecil fungsi gastrointestinal yang terpengaruh selama prosedur operasi. ${ }^{5,7,8}$

Analgetik non opioid yaitu anti inflamasi non steroid (AINS) dan parasetamol merupakan pilihan utama dalam manajemen nyeri ibu menyusui pascasalin. Parasetamol telah banyak digunakan sebagai analgetik pasca operatif baik sebagai dosis tunggal maupun kombinasi dengan beberapa analgetik lainnya. Parasetamol bersifat inhibtor COX-2 selektif, memberikan efek samping yang lebih minimal dibandingkan dengan AINS maupun opioid pada dosis teurapetik. Pada penelitian randomized, double blind, placebo-controlled menunjukkan pemberian parasetamol oral dosis tunggal memberikan efek anti nyeri yang efektif dalam kurun waktu 4 jam pasca operasi dengan efek samping minimal.,

Pemberian AINS seperti ketorolak efektif dalam mengurangi nyeri visceral pasca seksio sesarea dan memberikan efek yang lebih baik dibandingkan pemberian opioid, akan tetapi ketorolak bersifat inhibitor non selektifCOX-1 dan COX-2 sehingga dapat menimbulkan efek samping yaitu meningkatkan risiko perdarahan, iritasi organ gastrointestinal, dispepsia, dan mual. Selain itu, kombinasi ketorolak dengan patient-controlled epidural analgesia (PCEA) menimbulkan efek opiod sekitar $30 \%$. Efek samping setelah pemberian ketorolak dilaporkan lebih tinggi dibandingkan plasebo (16\% dan 13\%) meskipun tidak berbeda bermakna. ${ }^{7,10}$

Penelitian ini mencoba menganalisis perbandingan pemberian parasetamol $1000 \mathrm{mg}$ per oral dengan injeksi ketorolak $30 \mathrm{mg}$ intravena dalam 
mengatasi nyeri terhadap keberhasilan menyusui pasca seksio sesarea.

\section{METODE}

Penelitian ini merupakan single-blind, randomized controlled trial yang dilakukan di RSUD Banjarnegara dan RSUD Banyumas selama bulan Juli sampai dengan Oktober 2016. Adapun kriteria inklusinya adalah pasien yang akan dilakukan seksio sesarea pertama kali dengan regional anestesi, kehamilan tunggal, hamil aterm (37 - 42 minggu), tanpa komplikasi kehamilan, rawat gabung ibu bayi, bayi tidak mengalami fetal distress, dan bersedia mengikuti penelitian dan telah menandatangani formulir kesediaan. sedangkan kriteria eksklusi adalah pasien yang alergi terhadap parasetamol dan ketorolak.

Sampel penelitian dibagi menjadi dua kelompok yaitu kelompok kontrol dan kelompok intervensi dengan cara acak menggunakan komputer. Yang disebut kelompok intervensi adalah kelompok pasien yang mendapat parasetamol $1000 \mathrm{mg}$ per oral, sedangkan kelompok kontrol adalah kelompok pasien yang mendapat injeksi ketorolak $30 \mathrm{mg}$ intravena. Penelitian ini menggunakan amplop tertutup dengan nomer berurutan yang sudah diacak dengan komputer. Amplop berisi kertas yang menyebutkan analgetik yang diberikan. Karakteristik kedua kelompok data obstetri dan data medis dicatat.

Pemeriksaan fisik, obstetri dan tanda-tanda vital rutin dilakukan sebelum operasi. Pasca operasi pasien dilakukan pengukuran ulang tanda-tanda vital, kemudian pada masing-masing kelompok diberikan analgetik sebanyak 3 kali pemberian setiap 8 jam selama 24 jam pertama pasca operasi. Penilaian derajat nyeri dan keberhasilan menyusui dilakukan pada kedua kelompok mulai 6 jam dan 24 jam setelah operasi sebagai berikut, pertama pengukuran derajat nyeri dengan skor VAS, pasien diminta untuk menyebutkan skor nyeri dengan VAS scale, nilai VAS $\leq 4$ dianggap sebagai kelompok tidak nyeri dan nilai VAS $>4$ sebagai kelompok nyeri. Kedua melakukan penilaian keberhasilan menyusui dengan menggunakan LATCH charting system yang terdiri dari 5 komponen menyusui yaitu Latch tentang bagaimana pelekatan bayi terhadap payudara, Audible swallowing apakah ada suara yang ditimbulkan saat bayi menyusui, Type of nipple yaitu jenis puting ibu, Comfort adalah rasa nyaman saat ibu menyusui, dan Hold tentang bagaimana posisi ibu memegang bayi saat menyusui. Saat Ibu melakukan proses menyusui selama 10-15 menit dilakukan penilaian pada 5 komponen menyusui dengan skor numerik 0,1 atau 2 . Penilaian keberhasilan menyusui berdasarkan nilai total dari kelima komponen, apabila nilai $<10$ indikasi ibu tidak berhasil menyusui.

Penilai skor nyeri dan keberhasilan menyusui adalah dokter, bidan dan perawat yang berada di RS afiliasi. Data penelitian dianalisis dengan analisis univariat dan bivariat.

\section{HASIL DAN PEMBAHASAN}

Jumlah sampel penelitian sebanyak 86 pasien yang dibagi menjadi dua kelompok yaitu 43 pasien kelompok kontrol mendapat injeksi ketorolak 30 mg intravena dan 43 pasien kelompok perlakuan mendapat parasetamol $1000 \mathrm{mg}$ per oral. 
Tabel 1. Karakteristik subjek penelitian

\begin{tabular}{|c|c|c|c|c|c|c|c|}
\hline \multirow{2}{*}{ Variabel } & \multicolumn{4}{|c|}{ Perlakuan } & & \multirow{2}{*}{$\mathrm{n}$} & \multirow{2}{*}{$p$} \\
\hline & \multicolumn{2}{|c|}{ Parasetamol } & \multicolumn{2}{|c|}{ Ketorolak } & & & \\
\hline \multicolumn{8}{|l|}{ Usia } \\
\hline$\leq 25$ tahun & 18 & $(41,0 \%)$ & 14 & $(32,6 \%)$ & 32 & $(37,2 \%)$ & \multirow{2}{*}{0,67} \\
\hline$>25$ tahun & 14 & $(32,6 \%)$ & 16 & $(75,2 \%)$ & 30 & $(34,9 \%)$ & \\
\hline \multicolumn{8}{|l|}{ Paritas } \\
\hline Primigravida & 22 & $(51,2 \%)$ & 17 & $(39,5 \%)$ & 39 & $(45,3 \%)$ & \multirow{2}{*}{0,28} \\
\hline Multigravida & 21 & $(48,8 \%)$ & 26 & $(60,5 \%)$ & 47 & $(54,7 \%)$ & \\
\hline \multicolumn{8}{|l|}{ Pendidikan } \\
\hline Rendah & 29 & $(67,4 \%)$ & 26 & $(60,5 \%)$ & 55 & $(64,0 \%)$ & \multirow{2}{*}{0,50} \\
\hline Tinggi & 14 & $(32,6 \%)$ & 17 & $(39,5 \%)$ & 31 & $(36,0 \%)$ & \\
\hline \multicolumn{8}{|l|}{ IMT } \\
\hline Rendah & 8 & $(18,6 \%$ & 20 & $(46,5 \%)$ & 28 & $(32,6 \%)$ & \multirow{2}{*}{$0,006^{*}$} \\
\hline Tinggi & 35 & $(81,4 \%)$ & 23 & $(53,5 \%)$ & 58 & $(67,4 \%)$ & \\
\hline \multicolumn{8}{|l|}{ IMD } \\
\hline Ya & 0 & $(0,0 \%)$ & 0 & $(0,0 \%)$ & 0 & $(0,0 \%)$ & 1 \\
\hline Tidak & 43 & $(100 \%$ & 43 & $(100 \%$ & 86 & $(100 \%$ & \\
\hline
\end{tabular}

Pada tabel 1. dapat dilihat karakteristik subjek pada kedua kelompok. Pada kelompok usia $\leq$ 25 tahun terdapat 32 kasus $(37,2 \%)$, sedangkan untuk kelompok usia $>25$ tahun terdapat 30 kasus (34,9\%). Untuk kelompok paritas, terdapat 39 kasus $(45,3 \%)$ pada primigravida dan 47 kasus $(54,7 \%)$ pada multigravida. Berdasarkan tingkat pendidikan, sebagian besar partisipan berpendidikan rendah yaitu sebanyak 55 kasus $(64,0 \%)$ dan 31 kasus $(36,0 \%)$ berpendidikan tinggi. Untuk kelompok IMT rendah terdapat 28 kasus $(32,6 \%)$ dan IMT tinggi terdapat 58 kasus $(67,4 \%)$, sedangkan yang tidak dilakukan IMD sebanyak 86 (100\%) partisipan.

Tabel 2. Pengaruh pemberian analgetik terhadap nyeri

\begin{tabular}{lcccccc} 
& \multicolumn{4}{c}{ Kategori VAS } & $R R(95 \% \mathrm{Cl})$ & $p$ \\
& \multicolumn{2}{c}{ Tidak nyeri } & & Nyeri & & \\
Parasetamol 1000 mg & 29 & $(67,4 \%)$ & 14 & $(32,6 \%)$ & $1,16(0,84-1,16)$ & 0,37 \\
Ketorolak 30 mg & 25 & $(58,1 \%)$ & 18 & $(41,9 \%)$ & 1 & \\
\hline
\end{tabular}

Pada tabel 2 dengan analisis chi-square didapatkan hasil pemberian parasetamol $1000 \mathrm{mg}$ per oral memberikan efek tidak nyeri 1,16 kali lebih besar dibandingkan pemberian ketorolak $30 \mathrm{mg}$ intravena $(R R$ 1,16; 95\% Cl 0,84-1,16) meskipun tidak terdapat perbedaan bermakna secara statistik dengan nilai $p>0,05$. Untuk mengetahui pengaruh pemberian analgetik terhadap keberhasilan menyusui dengan variabel antara nyeri ditunjukkan pada tabel 3 dan tabel 4 . 
Tabel 3. Pengaruh pemberian analgetik terhadap keberhasilan menyusui

\begin{tabular}{lccccccc} 
& \multicolumn{4}{c}{ Menyusui } & \multirow{2}{*}{$R R(95 \% C l)$} & $p$ \\
\cline { 2 - 6 } & \multicolumn{2}{c}{ Berhasil } & \multicolumn{2}{c}{ Perlu dukungan } & & p \\
Parasetamol 1000 mg & 7 & $(16,3 \%)$ & 36 & $(83,7 \%)$ & $0,58(0,25-1,34)$ & 0,19 \\
Ketorolak 30 mg & 12 & $(27,9 \%)$ & 31 & $(72,1 \%)$ & 1 & \\
\hline
\end{tabular}

Tabel 4. Pengaruh pemberian analgetik dengan efek tidak nyeri terhadap keberhasilan menyusui

\begin{tabular}{lccccccc} 
& \multicolumn{4}{c}{ Keberhasilan menyusui } & & $R R(95 \% \mathrm{Cl})$ & $p$ \\
\cline { 2 - 5 } & \multicolumn{2}{c}{ Berhasil } & & Tidak berhasil & & & \\
Parasetamol 1000 mg & 5 & $(17,2 \%)$ & 24 & $(82,2 \%)$ & & $0,54(0,20-1,44)$ & 0,21 \\
Ketorolak 30 mg & 8 & $(32,0 \%)$ & 17 & $(68,0 \%)$ & & 1 & \\
\hline
\end{tabular}

Angka keberhasilan menyusui pada efek tidak nyeri setelah pemberian parasetamol 1000 mg per oral didapatkan hasil 0,54 kali lebih kecil dibandingkan ketorolak $30 \mathrm{mg}$ intravena, namun hasil ini tidak berbeda bermakna secara statistik ( $R R$ 0,54; 95\% Cl (0,20-1,44). Pada tabel 4 menunjukkan keberhasilan menyusui pada efek nyeri setelah pemberian parasetamol $1000 \mathrm{mg}$ per oral didapatkan hasil 0,64 kali lebih kecil dibandingkan pemberian ketorolak $30 \mathrm{mg}$ intravena, namun hasil ini tidak berbeda bermakna ( $R R 0,64 ; 95 \% \mathrm{Cl}(0,14$ 3,02 ). Untuk mengetahui keberhasilan menyusui berdasarkan masing-masing komponen dari LATCH charting system ditunjukkan pada tabel 5 .

Tabel 5. Pengaruh pemberian analgetik dengan efek nyeri terhadap keberhasilan menyusui

\begin{tabular}{lccccccc} 
& \multicolumn{4}{c}{ Keberhasilan menyusui } & & $R R(95 \% C l)$ & $p$ \\
\cline { 2 - 5 } & \multicolumn{2}{c}{ Berhasil } & \multicolumn{2}{c}{ Tidak berhasil } & & \\
Parasetamol 1000 mg & 2 & $(14,3 \%)$ & 12 & $(85,7 \%)$ & & $0,64(0,14-3,02)$ & 0,57 \\
Ketorolak 30 mg & 4 & $(22,2 \%)$ & 14 & $(77,8 \%)$ & & 1 & \\
\hline
\end{tabular}

Penilaian keberhasilan menyusui pada tabel 6 dengan LATCH charting system untuk masing-masing komponen menyusui didapatkan hasil pada kedua kelompok untuk komponen dengan nilai < 2 yaitu pada Latch (44,2\%), Audible swallowing (53,4\%), Type of nipple (16,3\%), Comfort (22,1\%) dan Hold (51,2\%), sedangkan untuk total skor 2 pada Latch (55,8\%), Audible swallowing (46,5\%), Type of nipple $(83,7 \%)$, Comfort $(77,9 \%)$ dan Hold $(48,8 \%)$.
Tabel 6. Keberhasilan menyusui dengan skor LATCH

\begin{tabular}{cccc} 
& & \multicolumn{3}{c}{ Total } \\
\cline { 3 - 4 } Skor & & $\mathrm{n}$ & $\%$ \\
$\mathrm{n}$ & $0-1$ & 38 & $44.2 \%$ \\
$\mathrm{~A}$ & 2 & 48 & $55.8 \%$ \\
& $0-1$ & 46 & $53.4 \%$ \\
$\mathrm{~T}$ & 2 & 40 & $46.5 \%$ \\
& $0-1$ & 14 & $16.3 \%$ \\
$\mathrm{C}$ & 2 & 72 & $83.7 \%$ \\
& $0-1$ & 19 & $22.1 \%$ \\
$\mathrm{H}$ & 2 & 67 & $77.9 \%$ \\
& $0-1$ & 44 & $51.2 \%$ \\
& 2 & 42 & $48.8 \%$
\end{tabular}


Tabel 7. Analisis bivariat hubungan IMT dengan keberhasilan menyusui pada kelompok parasetamol

\begin{tabular}{|c|c|c|c|c|c|c|}
\hline \multirow{2}{*}{ Variabel } & \multicolumn{4}{|c|}{ Keberhasilan menyusui } & \multirow{2}{*}{$R R(95 \% C l)$} & \multirow{2}{*}{$p$} \\
\hline & & Berhasil & & berhasil & & \\
\hline \multicolumn{7}{|l|}{ IMT } \\
\hline Rendah & 1 & $(12,5 \%)$ & 7 & $(87,5 \%)$ & $0,73(0,10-5,24)$ & 0,75 \\
\hline Tinggi & 6 & $(17,1 \% 0$ & 29 & $(82,9 \%)$ & 1 & \\
\hline
\end{tabular}

Pada tabel 7 diatas menunjukkan hasil pada kelompok parasetamol dengan IMT rendah angka keberhasilan menyusui 0,73 kali lebih rendah dibandingkan pada IMT tinggi, meskipun secara statistik tidak ada perbedaan bermakna dengan nilai $p>0,05$.
Tabel 8 menunjukkan angka keberhasilan menyusui pasca seksio sesarea pada kelompok ketorolak dengan IMT rendah 1,15 kali lebih tinggi dibandingkan pada IMT tinggi, meskipun secara statistik tidak ada perbedaan bermakna dengan nilai $p$ adalah 0,77

Tabel 8. Analisis bivariat hubungan IMT dengan keberhasilan menyusui pada kelompok ketorolak

\begin{tabular}{lcccccc}
\multirow{2}{*}{ Variabel } & \multicolumn{4}{c}{ Keberhasilan menyusui } & \multirow{2}{*}{ Berhasil } & \multicolumn{2}{c}{ Tidak berhasil } & & \\
\cline { 2 - 5 } IMT & & & & & & \\
Rendah & 6 & $(30,0 \%)$ & 14 & $(70,0 \%)$ & $1,15(0,44-3,00)$ & 0,77 \\
Tinggi & 6 & $(26,1 \% 0$ & 17 & $(73,9 \%)$ & 1 & \\
\hline
\end{tabular}

Pada perbandingan pemberian parasetamol $1000 \mathrm{mg}$ per oral dengan injeksi ketorolak 30 mg intravena didapatkan hasil tidak berbeda bermakna secara statistik pada kedua kelompok terhadap efek tidak nyeri $(R R$ 1,16; $95 \%$ Cl: 0,84$1,16 ; p 0,37)$. Median klirens dan volume distribusi parasetamol intravena $\left(10,9 \mathrm{~L} / \mathrm{jam} \mathrm{m}^{2}\right.$ dan 0,72 L/ $\mathrm{kg})$ dan ketorolak intravena $\left(2,11 \mathrm{~L} / \mathrm{jam} \mathrm{m}^{2}\right.$ dan 0,24 $\mathrm{L} / \mathrm{kg}$ ) pada pasien pasca seksio sesarea lebih tinggi dibandingkan kelompok wanita bukan pascasalin. Hal ini disebabkan karena perubahan disposisi obat selama kehamilan dan pascasalin akibat perubahan fisiologi dan metabolisme obat pada maternal. ${ }^{11}$ Selain itu dimungkinkan karena nyeri yang bersifat individual dan subjektif dengan multidimensional karakteristik serta dipengaruhi oleh faktor psikososial, emosional, kognitif, sosial dan budaya. ${ }^{12}$

Penelitian ini menunjukkan pada pengaruh efek tidak nyeri maupun nyeri setelah pemberian analgetik untuk kedua kelompok didapatkan hasil tidak berbeda bermakna terhadap keberhasilan menyusui. Hal ini berbeda dengan penelitian oleh Karlström et al. (2007) yang melibatkan 60 pasien pasca seksio sesarea di Swedia yang menyebutkan bahwa $62 \%$ pasien mengatakan nyeri dalam 24 jam pertama pasca operasi memberikan dampak negatif dalam proses menyusui dan merawat bayi. ${ }^{12}$ Nyeri luka seksio sesarea dan rasa tidak nyaman ibu akan menstimulasi pelepasan neurotransmiter katekolamin yang kemudian menekan sekresi prolaktin dan oksitosin, sehingga menyusui secara nyaman merupakan faktor penting dalam menstimulasi sekresi ASI melalui refleks isap bayi. Efek oksitosin yang dihasilkan saat proses menyusui dapat menurunkan sensitifitas nyeri, menurunkan reaksi inflamasi, dan merangsang proses penyembuh-an luka, selain itu pelepasan oksitosin ke sirkulasi darah otak juga menghasilkan perubahan adaptasi fisiologis pada ibu antara lain menurunkan kecemasan dan kadar kortisol. ${ }^{13,14}$

Pada penelitian ini menunjukkan $82,2 \%$ dan $68 \%$ pasien dengan efek tidak nyeri baik pada kelompok perlakuan dan kelompok kontrol masih memerlukan dukungan dalam menyusui. Berdasarkan penilaian keberhasilan menyusui dengan LATCH charting system untuk masing-masing komponen menyusui didapatkan hasil pada kedua kelompok untuk komponen dengan nilai < 2 pada Audible 
swallowing $(53,4 \%)$ dan Hold $(51,2 \%)$ dimana kedua komponen ini merupakan bagian dari posisi menyusui. Hal ini serupa dengan penelitian Cakmak dan Kuguoglu (2005) yang mengatakan bahwa ibu pasca seksio sesarea lebih memerlukan bantuan dalam memposisikan bayi pada periode awal menyusui, dimana kesulitan ini dapat menyebabkan pemahaman yang salah mengenai tidak adekuatnya sekresi ASI. ${ }^{15}$ Tidak dilakukannya IMD pasca seksio sesarea di dua RS afiliasi dapat menjadi salah satu faktor rendahnya angka keberhasilan menyusui pada penelitian ini. Pelepasan oksitosin kedalam sirkulasi darah maternal terjadi saat skin-to-skin contact dan proses menyusui yang menghasilkan respon fungsional yang berbeda. Kadar oksitosin pada ibu dan bayi juga dipengaruhi oleh metode persalinan dimana bayi dengan persalinan vaginal memiliki kadar oksitosin pada darah arteri umbilikal lebih tinggi dibandingkan dengan persalinan seksio sesarea: $69 \mathrm{pg} / \mathrm{mL}(20-315 \mathrm{pg} / \mathrm{mL})$ vs $33 \mathrm{pg} / \mathrm{mL}$ (9-195 pg/mL), dimana kadar oksitosin yang lebih rendah akan menyebabkan pengeluaran ASI yang tidak adekuat sehingga mempengaruhi keberhasilan menyusui. ${ }^{1,14}$

Pada penelitian ini menunjukkan pada kelompok ketorolak dengan IMT rendah 1,15 kali lebih tinggi dibandingkan IMT tinggi terhadap keberhasilan menyusui, meskipun tidak berbeda bermakna ( $R R$ 1,15; 95\% Cl: 0,44-3,00),. Ibu dengan IMT underweight dan obesitas lebih kecil angka keberhasilan inisiasi menyusui dibandingkan ibu dengan IMT normal, dimana penurunan inisiasi menyusui pada ibu obesitas dipengaruhi oleh faktor penurunan respon prolaktin, kesulitan pada mekanisme latch on dan memposisikan bayi saat proses menyusui, depresi maternal dan psikologis. ${ }^{9}$

Kekuatan penelitian ini dihitung ulang dengan data yang ada, dengan persamaan sebagai berikut:
Keterangan

$\mathrm{n} \quad$ : Jumlah sampel

Za : 1,64 (kesalahan tipe 1 ditetapkan 5\%)

P1 : Proporsi angka pengendalian nyeri pada ketorolak 0,67

P2 : Proporsi angka pengendalian nyeri pada parasetamol 0,58

$\mathrm{P} \quad: \underline{\mathrm{P} 1+\mathrm{P} 2}=0,63$

2

$Q: 1-P \quad=0,37$

$\mathrm{Q} 1: 1-\mathrm{P} 1=0,33$

$\mathrm{Q} 2: 1-\mathrm{P} 2=0,42$

Berdasarkan rumus tersebut didapatkan hasil kekuatan dari penelitian adalah 39,29\%. Diperlukan jumlah sampel yang lebih besar $\left(n_{1}=n_{2}=431\right.$ sampel) untuk meningkatkan kekuatan penelitian ini menjadi $80 \%$.

\section{KESIMPULAN DAN SARAN}

Pada penelitian ini disimpulkan bahwa pemberian parasetamol $1000 \mathrm{mg}$ tidak berbeda bermakna dibandingkan dengan injeksi ketorolak $30 \mathrm{mg}$ intravena terhadap nyeri dan keberhasilan menyusui pasca seksio sesarea.

Pemberian parasetamol $1000 \mathrm{mg}$ per oral dapat menjadi alternatif pilihan terapi analgetik pasca seksio sesarea meskipun efek tidak nyeri setelah pemberian obat tidak mempengaruhi keberhasilan menyusui pasca seksio sesarea, hal ini dapat disebabkan karena kekuatan penelitian yang belum menunjukkan $80 \%$. Perlunya penelitian lebih lanjut dengan sampel yang lebih besar $\left(n_{1}=n_{2}\right.$ = 431 sampel), efek samping dari pemberian obat dan variabel lain yang mempengaruhi keberhasilan menyusui pasca seksio sesarea yang belum diteliti untuk mendapatkan hasil yang lebih baik.

\section{DAFTAR PUSTAKA}

1. World Health Organization. Infant and young child feeding. Geneva: World Health Organization 2009

2. Fahriani R, Rohsiswatmo R, Hendarto A. Faktor yang Memengaruhi Pemberian ASI Eksklusif pada Bayi 
Cukup Bulan yang Dilakukan Inisiasi Menyusu Dini (IMD). Sari Pediatri 2014; 15(6): 394402.

3. Zanardo V, Canella A, Maone R, Straface G. Bonding and breastfeeding after a cesarean delivery. Early Hum Dev 2013; 89(SUPPL4): S56-7.

4. Kementerian Kesehatan Republik Indonesia. Profil Kesehatan Indonesia 2015. Jakarta: Kementerian Kesehatan RI 2016.

5. Chaplin J, Kelly J, Kildea S. Maternal perceptions of breastfeeding difficulty after caesarean section with regional anaesthesia: A qualitative study. Women Birth 2016; 29(2):144-52.

6. Mkontwana N, Novikova N. Oral analgesia for relieving post-caesarean pain. Cochrane Database Syst Rev 2015; 29(3): CD010450

7. Kwok S, Wang H, Sng BL. Post caesarean analgesia. Trends in Anaesth and Critical Care 2014; 4(6): 189194.

8. Bonnal A, Dehon A, Nagot N, Macloce V, Nogue E, Morau E. Patient-controlled oral analgesia versus nurse-controlled parenteral analgesia after caesarean section: A randomised controlled trial. Anaesthesia 2016; 71(5):535-43.

9. Thompson LA, Zhang S, Black E, Das R, Ryngaert M, Sullivan $S$, et al. The Association of Maternal Prepregnancy Body Mass Index with Breastfeeding
Initiation. Matern Child Health J 2012; 17(10): 184251.

10. Smith LA, Carroll D, edwards JE, Moore RA, McQuay HJ. Single-dose ketorolac and pethidine in acute postoperative pain: systematic review with metaanalysis. Br J Anaesth 2000; 84(1): 48-58.

11. Kulo A. Velde M, Calsteren K, Smits A, Hoon J, Verbesselt $R$, et al. Pharmacokinetics of intravenous ketorolac following caesarean delivery. Int J Obstet Anesth 2012; 21(4): 334-338.

12. Karlström A, Olofsson RE, Norbergh KG, Sjöling $M$, Hildingsson I. Postoperative pain after cesarean birth affects breastfeeding and infant care. J Obstet Gynecol Neonatal Nurs 2007; 36(5): 430-440.

13. Hsien C, Fu J, Long C. Factors Influencing Breast Symptoms in Breastfeeding Women After Cesarean. Asian Nurs Res 2011; 5(2): 88-98.

14. Moberg KU, Prime DK. Oxytocin effects in mothers and infants during breastfeeding. Infant 2013; 9: 201-206.

15. Cakmak H, Kuguoglu S. Comparison of the breastfeeding patterns of mothers who delivered their babies per vagina and via cesarean section: An observational study using the LATCH breastfeeding charting system. Int J Nurs Stud 2007; 44(7):11281137. 